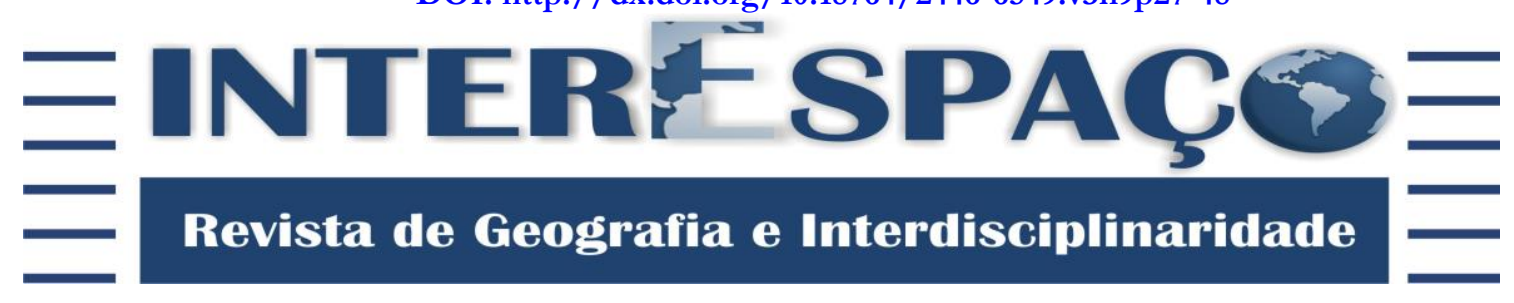

\title{
DE MOIRAS A TÂNATOS: considerações a respeito da morte e do morrer para os profissionais da enfermagem
}

FROM MOIRAS TO TÂNATOS: considerations about death and dying for nurses

DE MOIRAS A TÁNATOS: consideraciones acerca de la muerte y del morir para los profesionales de la enfermería

\section{Leonardo Mendes Bezerra}

Mestre em Ciências Ambientais pelo Centro Universitário de Anápolis - UNIEVANGÉLICA. Licenciado em Filosofia pela Pontifícia Universidade Católica de Goiás - PUC-GO. Professor Assistente da Universidade Estadual do Maranhão - UEMA/Campus Balsas. lydimo@live.com

\section{Ricardo Carvalho Neves}

Especialista em Saúde Pública e Saúde da Família pelo Instituto Atena/Sistema Don Bosco de Educação. Graduado em Enfermagem pela Universidade Estadual do Maranhão - UEMA/Campus Balsas. rick-leitor@hotmail.com

Recebido para avaliação em 05/05/2017; Aceito para publicação em 20/07/2017.

\section{RESUMO}

O processo de morte é inerente à vida e inevitável, precisando ser discutido para se desanuviarem os mitos que rondam esse assunto. A profissão de enfermagem lida diretamente com essa questão, uma vez que envolve a relação enfermeiro-paciente. Para tanto, existe a necessidade de preparar os acadêmicos para a atuação profissional, a fim de melhor agir no processo de morte-morrer do paciente, enfrentando-o de forma mais saudável e profissional possível. Diante disso, a pesquisa que ora se apresenta ocorreu com base em uma análise de conteúdo bibliográfica a fim de discutir a tanatologia, de modo a informar que os sentimentos mais comuns frente ao processo de mortemorrer consistiram no medo, na tristeza e na indignação, relacionados ao desconhecimento acerca do seu processo real. Por fim, destacou-se o sentimento de temor à morte, no qual se percebeu uma convergência com o senso comum que é notado em referência a essa questão.

Palavras-chave: Enfermagem; Morte; Pós-morte.

\section{ABSTRACT}

The death process is inherent in life and inevitable, needing to be discussed to unveil the myths that surround this theme. The nursing profession deals directly with this issue, since it involves the nurse-patient relationship. For this reason, there is the need to prepare the academics for professional performance, with the objective of better dealing in the process of death-die of the patient, facing it in a healthier and professional manner possible. Therefore, this research has occurred on the basis of a bibliographical analysis of content to discuss the thanatology, being that the most common feelings facing the death-die process were fear, sadness and indignation, related to ignorance about their real process. Finally, the sense of fear of death was perceived as a convergence with the common sense that is noted in reference to that question.

Keywords: Nursing; Death; Post-mortem. 
| De Moiras a Tânatos: considerações a respeito da morte e do morrer para os profissionais da Enfermagem |

| Leonardo Mendes Bezerra | Ricardo Carvalho Neves |

\section{RESUMEN}

El proceso de muerte es inevitable e inherente a la vida, necesitando de discusión para descubrir los mitos que rondan ese asunto. La profesión de enfermería se trabaja directamente con esta cuestión, ya que implica la relación enfermero-paciente. Para ello, existe la necesidad de preparar a los académicos para la actuación profesional, con el fin de actuar mejor en el proceso de muerte-morir del paciente, enfrentándolo de forma más sana y profesional posible. La investigación que se presenta se produjo basado en un análisis de contenido teórico para discutir la tanatología, para producir información que los sentimientos más comunes delante al proceso de muerte-morir consistieron en el miedo, la tristeza y la indignación pautas con el desconocimiento en lo que se refiere de su proceso real. Concluyendo, se destacó el sentimiento de miedo a la muerte, en el que se percibió una tendencia con el sentido común que se llama la atención en alusión a esa cuestión.

Palabras clave: Enfermería; Muerte; Post-muerte.

\section{INTRODUÇÃO}

O estudo científico da morte possui vários segmentos e aplicações, uma delas é analisar e entender os processos de morrer e do luto, pois a morte é um fato que certamente, em algum momento, será preciso lidar com suas consequências e dificuldades proporcionadas, seja de uma pessoa próxima, de um familiar e até mesmo de um paciente, como é o caso dos profissionais da saúde.

Os cursos da área da saúde apresentam, dentre muitos outros, um ponto que lhes é bastante peculiar: todos têm seu foco no bem-estar do ser humano. Seja no diagnóstico das enfermidades, na adequação da alimentação, recuperação dos movimentos e da comunicação, ouvindo os problemas e buscando suas respectivas soluções ou no cuidado da pessoa clinicamente doente, a vida é prioridade e não se almeja que ela transcorra com intercorrências graves, para os enfermeiros.

A enfermagem por se pautar na filosofia do cuidar da pessoa é, em meio às outras, a que mais se aproxima do indivíduo e as situações de morte estão intimamente ligadas, uma vez que são até inerentes a todas as profissões da saúde. Nesta profissão, o enfermeiro permanece em contato com o paciente durante mais tempo que os demais profissionais da saúde, acompanhando todo o processo do cuidado, de proteção, de promoção à vida, de valorização e também dos cuidados no processo de morte e do morrer.

Porém, tal processo, mesmo sendo inerente a essa profissão, não é discutido no curso de graduação, sendo debatido apenas em raros momentos, cujo conhecimento não é tão abrangente a ponto de preparar o profissional em formação para futuras experiências.

Diante disso, este trabalho objetivou fazer um estudo teórico a respeito do processo do morrer e da morte. A metodologia centrou-se na pesquisa bibliográfica analítica, fundamentada nas propostas de Bardin (2016). Primeiramente realizaram-se 
| De Moiras a Tânatos: considerações a respeito da morte e do morrer para os profissionais da Enfermagem|

| Leonardo Mendes Bezerra | Ricardo Carvalho Neves |

leituras exploratórias em relação aos conteúdos das temáticas abordadas e posteriormente organizou-se em categorias para melhor dividir a discussão.

\section{PROCEDIMENTOS, RESULTADOS E CONSIDERAÇÕES}

A partir da leitura exploratória selecionaram-se os principais conteúdos. Foram buscadas as informações-chave - palavra ou frase - relacionadas à temática da tanatologia. Após a realização da leitura exploratória agruparam-se os recortes por afinidades de categorias, elaborando, assim, as pré-categorias. Com base nas frequências de repetições informativas foram elaboradas as informações das pré-categorias, conforme explicitado na Tabela 1:

Tabela 1 - Frequência das Pré-categorias

\begin{tabular}{l|c}
\hline Pré-categorias & Frequência \\
\hline Visão mitológica, mística e religiosa da morte & 32 \\
A morte como representação da vontade de Deus e do divino & 40 \\
A força da morte e a fragilidade humana & 44 \\
O descontrole, os sacrifícios e os fracassos no processo de controlar a morte & 47 \\
O papel do Enfermeiro no momento da má notícia (notícia da morte) e a & 48 \\
humanização no processo de morte-morrer & \\
\hline
\end{tabular}
Fonte: BEZERRA, L. M.; NEVES, R. C. (2014).

Após o quantitativo de informações agrupadas e expressas na Tabela 1, iniciou-se o processo fenomenológico de percepções analítico-empíricas com a literatura explorada. Esta análise consistiu em fazer uma conexão que envolvesse os pressupostos teóricos e as percepções empíricas, convertidas na análise reflexiva para produzir uma diretriz teórica fundamentada nos itens significantes da pesquisa. Assim, os resultados dessas percepções se converteram nas seguintes categorias, conforme apresentadas no Quadro 1:

Quadro 1 - Síntese das Categorias Analíticas

\begin{tabular}{|c|c|}
\hline Ordem & \multicolumn{1}{|c|}{ Categoria analítica } \\
\hline $1^{\text {a }}$ categoria & A Tanatologia e a compreensão da Morte através da História \\
\hline $2^{\text {a }}$ categoria & A compreensão da Morte na atualidade \\
\hline $3^{\text {a }}$ categoria & O profissional de Enfermagem perante a Morte dos pacientes \\
\hline $4^{\text {a }}$ categoria & A preparação do acadêmico para o processo de Morte morrer \\
\hline
\end{tabular}


|De Moiras a Tânatos: considerações a respeito da morte e do morrer para os profissionais da Enfermagem|

| Leonardo Mendes Bezerra | Ricardo Carvalho Neves |

A primeira categoria diz respeito à compreensão mitológica e histórica da morte; a segunda, à percepção da morte na atualidade; a terceira categoria discutiu a morte na visão dos profissionais da enfermagem; e, por último, a quarta categoria analisou a preparação dos acadêmicos de enfermagem para o processo de morte e de morrer.

PRIMEIRA CATEGORIA: a Tanatologia e a compreensão da Morte através da História

Mitologicamente, na cultura grega antiga, as Moiras eram as irmãs (Cloto, Láquesis e Átropos) que determinavam os destinos da vida humana e dos deuses. A responsabilidade de Cloto era tecer o fio da vida. Láquesis enrolava o fio tecido e sorteava as atribuições que se ganhava em vida. Já Átropos, juntamente com Tânatos, eram responsáveis por determinar o fim da vida, cortando o fio vital (WEST, 1966).

Tânatos era um deus da mitologia grega que representa a morte e, para a psicanálise freudiana, é a personificação mítica de um impulso instintivo do inconsciente que busca a destruição ou a morte, ou seja, é a própria pulsão de morte. Diante disso, surge o termo "Tanatologia", que é a ciência dedicada ao estudo da morte e de seus processos. O referido termo vem do grego e significa thanatos, o deus da morte; e logos, estudo (AGRA; ALBURQUERQUE, 2008).

A morte é compreendida como a última etapa da vida. Após esta, deixa-se de existir materialmente, assim como é o fim dos pensamentos, sonhos e sentimentos. Com esse pressuposto, fundamentado no cogito e na dualidade cartesiana, o processo de morrer também é a única certeza absoluta aceita por todos os humanos, não sendo negada em nenhuma civilização ou ideologia filosófica. Isso, de certo modo, faz com que a morte assuma um papel significativo na história da humanidade, pois é parte integrante da existência humana.

Os seres humanos, como todos os seres vivos marcados pela passagem da vida e que buscam soluções possíveis para os problemas, erroneamente lutam contra a ideia de finitude. Busca-se, ao máximo, um alívio possível para o paradoxo existencial que se apresenta frente à dicotomia viver e morrer. Esta situação tem sido notável na cultura ocidental e aumenta, de certa forma, essa angústia, tornando mais difícil a lida com a situação (BELLATO; CARVALHO, 2005).

Nos estudos de Santos e Bueno (2010), a morte, na maioria das vezes, é vista como algo sobrenatural, o terror, o castigo, a dor, assim como outros significados negativos 
| De Moiras a Tânatos: considerações a respeito da morte e do morrer para os profissionais da Enfermagem |

\section{| Leonardo Mendes Bezerra | Ricardo Carvalho Neves |}

peculiares da cultura ocidental. Entretanto, nos dias atuais, percebe-se que a morte não representa um consenso no imaginário do ser humano, replicando em cada mente uma concepção muito distinta que vai simplesmente do fim até os fenômenos mais complexos e únicos (CANTÍDIO et al., 2011; AGRA; ALBUQUERQUE, 2008).

O conceito tradicional de morte biológica, estabelecido pela filosofia mecanicista de René Descartes, que embasou a ciência moderna, definida como o instante em que o coração para de pulsar, está ultrapassado. Hoje, ela é vista como um processo mais complexo que envolve outros processos vitais e cerebrais, como um fenômeno progressivo e não mais como um momento ou evento (JÚNIOR; ELTINK, 2011). Compreende-se, então, que o estudo da tanatologia faz-se importante no sentido de compreender o que é a morte, abdicando de pré-conceitos e mitos que rondam essa etapa natural da vida, além de proporcionar uma oportunidade de reflexão sobre a vida e a finitude humana.

A conjuntura ocidental que ultrapassa as gerações a respeito da temática é abordada por Cantídio et al. (2011, p. 17), ao informar que a morte

é um tema visto sob diferentes dimensões, sem permitir afirmar verdades absolutas, pois, quando abordada, desperta curiosidade, provoca desconforto e vem sempre acompanhada de muitas perguntas para as quais se encontra a incontestável resposta de que o morrer é inevitável, intrínseco à vida e representa a certeza de que a todo nascimento associase um momento de fim. Trata-se de um tema circundado pela incerteza e pelo medo daquilo que não se pode prever ou conhecer, no conceito dos que enfrentaram a Morte como limite da vida. Todos os atributos da Morte desafiam as mais distintas culturas, as quais buscam respostas nos mitos, na filosofia, na arte e nas religiões e na ciência para compreender o desconhecido e remediar a dor gerada pelo evento.

Uma das características do ser humano é a atribuição de significados e valores que ele imprime às coisas, além da incessante busca por respostas e explicações para as questões que rodeiam as experiências de vida. Isso fez com que o conceito de morte mudasse e, em cada período histórico, fosse visto pelas pessoas de forma diferenciada, o que incluía influências decorridas de sua cultura, credo e estilo de vida (AGRA; ALBURQUERQUE, 2008; COMBINATO; QUEIROZ, 2006).

Percebe-se, portanto, que a humanidade, através da história, sempre buscou desvendar os mistérios que envolvem a existência humana, a origem e o fim. Ideia essa que reforça as reflexões de Moreira e Lisboa (2006) e Carvalho et al. (2006), ao destacarem que ao longo da evolução da humanidade a compreensão do processo de morrer e de morte passou por várias intepretações para atender às necessidades das sociedades. Por isso, o significado da morte varia necessariamente no decorrer da história e entre as diferentes culturas humanas. A importância e o sentido dados à morte sofriam influência das 
|De Moiras a Tânatos: considerações a respeito da morte e do morrer para os profissionais da Enfermagem|

| Leonardo Mendes Bezerra | Ricardo Carvalho Neves |

mudanças que ocorriam em cada civilização, o que fez com que o morrer assumisse um caráter distinto.

\begin{abstract}
Para os antigos gregos, a incineração determinava dois tipos de mortos: o cadáver do homem comum e o cadáver dos grandes heróis. Ao anônimo cabia o crematório coletivo e o depósito de suas cinzas em vala comum. Os corpos falecidos dos heróis eram cremados na cerimônia da bela morte, onde os seus feitos no campo de batalha eram enaltecidos. A própria morte seria a prova de sua virtude, tornando-o um indivíduo cuja vida é digna de ser lembrada (AGRA; ALBUQURQUE, 2008, p. 20).
\end{abstract}

Na Mesopotâmia Antiga, o sepultamento de um falecido era carregado de hábitos e significados, através dos quais o corpo da pessoa era enterrado com todas as marcas de sua vida pessoal, o que incluía vestimentas, pertences, insígnias e comidas preferidas. Para os hindus, a cremação tinha o objetivo de apagar todos os traços existenciais do morto, pois o cadáver era totalmente queimado e as cinzas lançadas à água ou ao vento. Como se o fato de ter vivido fosse um erro e, a morte, uma penitência por tal transgressão (AGRA; ALBUQUERQUE, 2008; GIACCOIA JÚNIOR, 2005).

No Egito Antigo havia a crença na vida após a morte, e isso levou ao tão conhecido costume de mumificar os corpos e guardá-los em tumbas suntuosas, cercados por seus pertences, a fim de que pudesse usufruir da segunda vida com toda a regalia que tivesse antes de morrer (MOREIRA; LISBOA, 2006). Hábito também observado nas civilizações pré-colombianas. A morte nessa época era um evento muito respeitado e as cerimônias fúnebres envolviam muito trabalho e tempo.

Remotamente na História, Carvalho et al. (2006) citam o papel marcante que a Igreja sempre representou na hora da morte com seus rituais, os quais eram, até o século XIII, sem dramaticidade ou gestões de emoções excessivas. Após este século, o padre passou a ocupar a cena prioritária e não apenas o defunto, pois, após o ultimo suspiro, o morto não pertence mais aos familiares, seus pares ou companheiros, e sim passa a pertencer à igreja. Na segunda fase da Idade Média, as poucas mudanças que ocorreram consistiram apenas na preocupação humana com eventos pós-morte, sendo eles o Juízo Final, a vida eterna no céu ou o castigo por seus pecados no inferno, informações essas muito difundidas nas teorias filosóficas e teológicas dos filósofos Agostinho e Aquino (PINHO, 2008).

As pessoas que acompanhavam os moribundos tinham um maior contato com o processo morte-morrer, pois o vivenciava continuamente. O conhecimento da morte era uma rotina e nenhuma criança crescia sem ter tido a experiência de ver, pelo menos, uma cena de morte. Isso, de certa forma, sensibilizava e conscientizava as crianças a tentarem 
| De Moiras a Tânatos: considerações a respeito da morte e do morrer para os profissionais da Enfermagem|

| Leonardo Mendes Bezerra | Ricardo Carvalho Neves |

entender o processo de morte-morrer, uma vez que toda a comunidade participava desse acontecimento e, por ocorrer com alguém tão próximo, era possível que fizessem uma identificação com o outro (AGRA; ALBUQUERQUE, 2008).

Em meados do século XVIII a morte passa a ter uma conotação mais dramática

\begin{abstract}
Em que predomina o culto ao cemitério e o luto exagerado, no qual o protagonista passa a ser a família e não mais o morto. Tal situação perdurou pelo século XIX, sendo que os parentes omitiam ao doente a gravidade do seu estado na tentativa de poupá-lo, transformando a morte em tabu, rigorosamente afastada, principalmente das crianças (TAKAHASHI et al., 2008, p. 23).
\end{abstract}

Percebe-se que nessa época as pessoas pouco se ocupavam com a possível chegada de sua morte e preocupavam-se com a morte dos parentes e das pessoas queridas, pois estas deixariam saudades e lembranças (OLIVEIRA; QUINTANAL; BERTOLINO et al., 2010). No percurso da história da humanidade viu-se que o processo de morte-morrer passou por várias transformações valorativas, conforme a cultura de cada lugar do mundo. Diante disso, estabelecem-se os seguintes questionamentos: qual é o entendimento atual da morte? Como o processo de morte-morrer é encarado pelas pessoas? Essas indagações são respondidas na próxima categoria analítica.

\title{
SEGUNDA CATEGORIA: a compreensão da morte na atualidade
}

Atualmente a morte é tratada como tabu e, com o passar dos tempos, deslocou-se do espaço da casa para o do hospital. Assim, a mesma deixou de constituir-se como um fenômeno natural, para se transformar em um evento frio, escondido e profundamente indesejado. Algo que era tão presente, conhecido e familiar no passado, se apaga e desaparece, tornando-se vergonhosa e até mesmo incogitada; vira um inconveniente e, portanto, a sua demonstração pública não é mais bem-vista (BELLATO; CARVALHO, 2005).

Com a Revolução Industrial, o mundo passou a ser regido sob um novo modelo econômico, no qual a figura humana era vista mais como mão de obra, importante e imprescindível para manter e alavancar o desenvolvimento das nações (AGRA; ALBUQUERQUE, 2008). Com tal crescimento, inicialmente desordenado, os seres humanos despreparados, vindos principalmente do meio rural, tornaram-se vulneráveis às doenças, principalmente as infecciosas e parasitárias, uma vez que as cidades não tinham infraestrutura que comportasse essa migração repentina de pessoas. 
|De Moiras a Tânatos: considerações a respeito da morte e do morrer para os profissionais da Enfermagem |

| Leonardo Mendes Bezerra | Ricardo Carvalho Neves |

As cidades não estavam preparadas para o grande fluxo de pessoas, não existia um planejamento sanitário, a água e os dejetos não tinham um tratamento adequado, com valas conduzindo materiais sem nenhuma estruturação prévia, contaminando os lençóis freáticos e proporcionando um aumento no número de roedores, mosquitos, etc., o que conseqüentemente, acarretou um aumento das doenças infecto-parasitárias (MOREIRA; LISBOA, 2006, p. 32).

Foi nesse ínterim que a morte passou a ser institucionalizada, quer dizer, havia um local próprio onde os doentes ficariam, pois se temia que eles contaminassem os sadios e atrapalhassem o impulso da economia que crescia vertiginosamente. Entretanto, a política de saúde da época era baseada em normas de higiene, sendo a morte e o moribundo inseridos nesse contexto. Desse modo, os doentes foram transferidos para o hospital, um lugar onde ficariam sob os cuidados especiais para que se recuperassem logo e pudessem voltar a contribuir para o progresso industrial (MOREIRA; LISBOA, 2006). Em uma sociedade que valoriza seus cidadãos pelo potencial de trabalho, pela capacidade de produção destes, as doenças e a morte aparecem como uma força contrária e incômoda ao processo de acumulação e produção de riqueza (OLIVEIRA; AMORIM, 2008).

A partir da segunda metade do século XX passa a ocorrer uma mudança brusca, na qual a morte deixa de ser familiar e passa a ser um objeto interdito, o que Caputo (2008) discursa afirmando que um fator material importante que impulsionou esta transformação foi a transferência do local da morte. A morte não ocorre mais no domicílio, no meio dos familiares, mas solitário no hospital, com pouca assistência dos profissionais da saúde. Assim, nas últimas décadas, com o aprimoramento e o desenvolvimento das tecnologias e da ciência médica, a morte acontece preferencialmente no ambiente hospitalar, cercada de aparelhos, monitores e recursos humanos especializados, capazes de assegurar um processo de morte assistida e, em sua maioria, sem dor (SILVA, 2009; SHIMIZU, 2007).

A medicina, subsidiada pelos avanços tecnológicos, proporcionou uma mudança na representação social da Morte. Hoje em dia dificilmente se morre em casa, rodeado por familiares e amigos, com serenidade para despedir-se da vida e, sim, às escondidas, trancafiado em um ambiente hospitalar, considerado neutro, e na maioria dos casos sozinho ou acompanhado de pessoas estranhas (TAKAHASHI et al., 2008, p. 36).

Este quadro instalado fez com que as pessoas se distanciassem do processo mortífero, ficando cada vez mais ausentes e arredios quanto a ela. Caputo (2008, p. 12), defende que:

[...] os psicanalistas existenciais apontam que se no início do século XX o grande tabu se dava em relação ao sexo, no final do referido século o grande tabu é ligado à morte. $\mathrm{Na}$ atualidade é comum as crianças receberem informações 
|De Moiras a Tânatos: considerações a respeito da morte e do morrer para os profissionais da Enfermagem|

| Leonardo Mendes Bezerra | Ricardo Carvalho Neves |

sobre sexualidade, porém quando se trata da Morte esta é mascarada relacionando-a com uma 'viagem', 'descanso'.

Em relação à morte, o medo é atualmente o sentimento mais presente nas pessoas, seja condicionado pelo fator oculto que ela representa ou pela questão sobrenatural. $O$ homem atual tende a temer aquilo que não conhece e não tem como experienciar, como é o caso da morte. Conforme Takahashi et al. (2008), a atual conjuntura social do ocidente presencia uma crise contemporânea da morte-morrer. Movidos pelo progresso tecnológico vertiginoso, através do qual se encontra solução para tudo e, o que ontem era novo, amanhã já é ultrapassado, o homem frustra-se por não conseguir solucionar a morte e o tão sonhado "elixir da juventude" nunca ser alcançado.

As características do sistema econômico capitalista fizeram com que a morte fosse vista não como uma certeza, mas como um obstáculo, ou uma adversária na vida da pessoa, e que podia ser vencida, individual ou coletivamente. A partir do momento que o corpo não possui valor como instrumento de trabalho, este não atende ao sistema, sendo as questões que remetem ao fenômeno morte relegadas a um segundo plano, não pensadas pela sociedade e muito menos valorizadas (MOREIRA; LISBOA, 2006). Outra característica desse modo de agir do homem contemporâneo acerca do processo de morrer, se mostra pela eufemização ou indiferença a esse processo, de acordo com Bellato e Carvalho (2006, p. 38):

A presença da morte é dissimulada pela equipe de saúde que rapidamente prepara o corpo e legaliza o novo status do morto por meio do atestado de óbito. Até as palavras denunciam essa ocultação, ao invés de simplesmente dizer que alguém morreu, usam a expressão, impessoal e menos angustiante, "foi a óbito”.

A negação da Morte é perceptível em todos os setores da sociedade, até mesmo entre os profissionais de saúde, que evitam falar sobre ela, seja por questões pessoais ou hábito de vida. Percebe-se que, na atuação dos enfermeiros, a morte tem deixado paulatinamente de ser um tabu e tem se mostrado muito presente nas práticas profissionais, já que é o enfermeiro que lida com todos os processos de acompanhamento e a sistematização do cuidado com a pessoa e trabalha visando proporcionar uma morte mais tranquila, quando não se tem recursos para garantir e promover a saúde. Neste sentido, a palavra morte deixou de ser utilizada na área científica da saúde, pois, na linguagem instrumentalizada, a morte se refere a "óbito", dando a impressão de ser uma palavra mais sutil e menos agressiva, mas que não muda os sentimentos da equipe, tampouco das pessoas que ouvem esse termo. 
| De Moiras a Tânatos: considerações a respeito da morte e do morrer para os profissionais da Enfermagem |

\section{|Leonardo Mendes Bezerra | Ricardo Carvalho Neves |}

Júnior e Eltink (2011) mencionam que, na atualidade, a maioria das pessoas não aceita a morte como algo natural e inevitável e tenta enganá-la ou mesmo adiá-la, concentrando esforços para manter-se eternamente jovem, recorrendo ao que a medicina oferece, não se importando com custos ou sacrifícios aderentes. Assim, cabe informar que, para Bernier e Hirdes (2007), o critério de morte comumente utilizado pela medicina é a avaliação da função cerebral, ou seja, se houve parada das funções vitais a pessoa pode até ser mantida "viva" por meio de aparelhos, pois, com os avanços da ciência e da tecnologia, tornou-se possível manter as funções cardíacas e respiratórias através de aparelhos, enquanto nada se pode fazer para sustentar funções cerebrais responsivas.

Toda essa composição que se deu para a morte é nada mais que uma saída para a árdua aceitação da mesma. Segundo Agra e Albuquerque (2008, p. 16):

\footnotetext{
Mesmo sabendo que a Morte é a única certeza absoluta da existência humana, é angustiante e de difícil aceitação pelas pessoas, expressando-se pela dificuldade de lidar com o limite da vida. Ainda assim, sabendo que a morte é um fenômeno natural recusamos como sendo pessoal e inevitável, sendo comum, as pessoas morrerem isoladas, encerradas nos hospitais, longe dos seus. Assim, adiamos o confronto em lidarmos com a nossa própria morte.
}

Característica verificada principalmente na cultura ocidental, que ao longo do tempo acabou por dar menos atenção e importância à morte, talvez numa medida de confrontá-la ou tentar superá-la. Aliado a este pensamento vimos que o homem também utiliza outro meio para enfrentar a morte, que se baseia na

[...] ausência da reflexão sobre a morte, ou até mesmo o não falar sobre ela, representa o não pensar na perda dos que ficam e também na dor da solidão. No entanto, ao utilizar esse mecanismo de defesa, pode-se criar uma armadura protetora, que se manifesta pela insensibilidade e frieza prejudicando, assim, o desenvolvimento do profissional, impedindo-o de crescer humana e profissionalmente (TAKAHASHI et al., 2008, p. 37).

Porém, com isso, o enfermeiro corre o risco de tornar-se apenas uma máquina de cuidados, direcionados apenas ao paciente vivo, prejudicando a sua face humana. Em algum momento, ele poderá deixar o seu ambiente de trabalho e inevitavelmente levará o seu novo jeito de ser para o convívio social, o que lhe trará problemas de enfrentamento, quando essa situação suceder-se com um dos seus (JÚNIOR; ELTINK, 2011; CANTÍDIO et al., 2011) .

É muito comum perceber nos discursos dos profissionais da enfermagem que existem enfermeiros que preferem não pensar na morte-morrer, porquanto muitos não estão preparados cientificamente e empiricamente para enfrentar com menos emotividade a 
| De Moiras a Tânatos: considerações a respeito da morte e do morrer para os profissionais da Enfermagem|

| Leonardo Mendes Bezerra | Ricardo Carvalho Neves |

etapa final da vida das pessoas. Desse modo, o processo de morte-morrer é observado pelos enfermeiros como algo que não se pode evitar devido a sua implacabilidade e invencibilidade. Contudo, questiona-se: quais são as atribuições do enfermeiro no processo de morte dos pacientes? Para responder sobre essa demanda, a terceira categoria analítica apresenta uma reflexão acerca do referido processo de morte-morrer, muito comum e, ao mesmo tempo, bastante problematizado no meio científico e empírico.

\section{TERCEIRA CATEGORIA: o profissional de Enfermagem perante a morte dos pacientes}

Apesar de a morte fazer parte do cotidiano dos profissionais da Enfermagem, observa-se que esses profissionais apresentavam dificuldades para prestar cuidados ao paciente e interagir com seus familiares frente à possibilidade da morte, sendo esta geradora de reações e sentimentos causadores, muitas vezes, de sofrimento nesses trabalhadores. Deste modo, Mota et al. (2011) destacam que esses profissionais vivenciam o conflito de ter a responsabilidade pelo cuidado ao paciente em processo de morte e a vontade de curar e restabelecer a saúde daquele a quem se cuida como algo impossível.

Percebeu-se que, na visão de Custodio (2010) e Bellato et al. (2007), essa situação cria um paradoxo na mente do profissional de Enfermagem, porque concomitantemente ele luta para oferecer aquilo que sua formação o instruiu, que é concentrar esforços para manter a vida do paciente, com o fato de ter que propiciar um fim aceitável e digno, no caso dos pacientes terminais.

O morrer nunca é totalmente aceito por todos. O que ameniza, na maioria das vezes, é saber que o doente já tinha idade avançada, ou um quadro já terminal, no qual apenas cuidados paliativos seriam eficazes, sem intenção de evitar o fim, ainda com o objetivo de proporcionar o término da vida de maneira tranquila, indolor e, acima de tudo, humanamente digna. Todavia, quando este paciente é jovem, principalmente criança ou adolescente, essa conformidade não suaviza o impacto e o fator idade torna-se um peso a mais para a família e para o profissional que o acompanhava (CANTíDIO et al., 2011; JÚNIOR; ELTINK, 2011).

Como assente, Costa e Lima (2005, p. 40), ao dizer que

No hospital encontramos um grande número de pacientes, entre eles crianças e adolescentes, com prognóstico grave e doença em fase avançada, sendo a problemática da morte uma constante. [...] A morte da criança e do adolescente é interpretada como interrupção no seu ciclo biológico e isso provoca na equipe 
| De Moiras a Tânatos: considerações a respeito da morte e do morrer para os profissionais da Enfermagem|

| Leonardo Mendes Bezerra | Ricardo Carvalho Neves |

de enfermagem sentimentos de impotência, frustração, tristeza, dor, sofrimento e angústia durante o processo de terminalidade.

Mota et al. (2011) verificaram diversas reações e sentimentos dos membros das equipes de enfermagem dos setores do hospital no qual atuaram frente à morte. A maioria fica em silêncio, uns choram, outros se fazem indiferentes, mas todos sempre se questionam em busca de uma justificativa que explique a finitude do homem e o porquê de todos terem um fim comum. Outros sentimentos também são citados em Júnior e Eltink (2011, p. 23), ao afirmarem que "assistir o paciente neste momento é difícil, pois suscita sensação de tristeza, frustração, impotência e até mesmo culpa por falhas na assistência prestada, dando a sensação de que tudo que foi feito não foi o bastante, que poderia ter sido feito sempre mais e melhor".

Neste sentido, quando está com o paciente nesse momento, o enfermeiro tende a compartilhar das mesmas emoções do paciente e da família. Outrossim, Silva (2009) destaca que os profissionais de Enfermagem experimentam de maneira potencializada esses sentimentos conflitantes, embora faça parte do cotidiano de trabalho, muitos profissionais encontram dificuldade em encarar a morte como um processo natural, considerando-a como fracasso profissional.

Os maiores problemas que os profissionais enfermeiros enfrentam consistem: na falta de instrução científica para o dado o momento; as condições de trabalho que, na maioria das vezes, são precárias e falhas com enfermarias superlotadas e desorganizadas; jornadas de trabalho que também são, por vezes, longas e cansativas. Todos estes fatores contribuem para o estresse físico e mental do profissional, o qual opta pela indiferença, para se manter o mais saudável possível (SANTOS; BUENO, 2011).

Assim, o cuidar do paciente grave pode se tornar impessoal, fato este às vezes necessário para assegurar a saúde mental. Culturalmente, nem mesmo os enfermeiros estão preparados para isso e encontram na indiferença a melhor forma de se precaver dos impactos causados pelo processo de morte. Conforme observa Silva e Ruiz (2003, p. 14), "negar e banalizar a Morte é saída efêmera ao profissional de saúde, fazendo-lhe agir isento de envolvimento emocional algum. Essa estratégia errônea confronta-o com as falhas de suas defesas, perpetuando a sua angústia não expressa".

Uma vez que o ser humano geralmente desenvolve um mecanismo de defesa e proteção contra o sofrimento, o processo de morrer e morte torna-se gradativamente trivial. Isto é, o distanciamento e endurecimento das relações frente à morte e ao paciente terminal viram algo estranhamente natural, considerados comum e rotineiro (MOREIRA; 
| De Moiras a Tânatos: considerações a respeito da morte e do morrer para os profissionais da Enfermagem |

| Leonardo Mendes Bezerra | Ricardo Carvalho Neves |

LISBOA, 2006). Estudos mostram que esse quadro apresentado causa um problema de ordem pública para o país, pois:

\begin{abstract}
Essa dificuldade em se lidar com a morte tem ocasionado uma gama de problemas que atinge diretamente o sistema de saúde público e privado do país, especialmente em virtude do adoecimento de seus profissionais. Adoecimento este, decorrente do desgaste emocional, que favorece o desenvolvimento da Síndrome de Burnout, descrita como a reação final do indivíduo face às experiências estressantes acumuladas ao longo do tempo de determinada atividade laboral, obtendo uma modificação do cuidar, produzindo na saúde, enfermeiros frios e indiferentes (SANTOS; BUENO, 2011, p. 25).
\end{abstract}

Ao considerar que os profissionais de saúde e, entre eles, os enfermeiros, têm sua formação acadêmica concentrada na preservação da vida, particularmente na cura das doenças, tirando daí sua maior fonte de gratificação quando em seu cotidiano de trabalho necessitam lidar com situações que envolvam o morrer e a morte, é compreensível que se sintam despreparados e tendam a se afastar delas (BELLATO et al., 2007).

O sentimento de fracasso também se faz presente porque a morte lhes aparece como algo que vem desmanchar tudo aquilo que se fez em prol do bem-estar do paciente. Muitas vezes, estudantes e profissionais sentem-se impotentes diante da perda do paciente que está sendo assistido ou reanimado. Júnior e Eltink (2011) e Silva e Ruiz (2003) coadunam da mesma ideia quando abordam que o sentimento de impotência e de fracasso não se traduz somente como um fracasso nos cuidados prestados, mas como uma derrota diante da morte e de sua missão por ser um profissional da área da saúde, que é a de salvar o paciente, minimizar sua dor e sofrimento, ou seja, trazer-lhe a vida.

Conforme essas premissas explicita-se a necessidade de um melhor preparo profissional para o enfermeiro atuar no processo de morte-morrer, uma vez que não é fácil para estes profissionais - que lidam com o cuidado, a promoção e educação para a vida e para os cuidados com a saúde - encararem a morte como um fracasso da ciência e do profissional. Portanto questiona-se: na graduação em Enfermagem, os acadêmicos estão sendo preparados para o processo de morte-morrer, uma vez que o curso, assim como os demais cursos da área das ciências da saúde, visa à vida do paciente e não a morte?

A quarta e última categoria analítica foi elaborada justamente para atender aos anseios deste questionamento, por apresentar a necessidade de uma formação diferenciada que desenvolva competências e habilidades nos acadêmicos de enfermagem na sua formação para o processo final da vida, morte-morrer. 
| De Moiras a Tânatos: considerações a respeito da morte e do morrer para os profissionais da Enfermagem|

|Leonardo Mendes Bezerra | Ricardo Carvalho Neves |

\section{QUARTA CATEGORIA: a preparação do acadêmico para o processo de morte-} morrer

Nos últimos anos, vários estudos sobre as concepções, reflexões, os sentimentos e o preparo de estudantes de Enfermagem frente às situações que envolvem a morte e o morrer têm sido publicados, havendo consenso entre os pesquisadores de que pouca atenção vem sendo dada à temática na formação do enfermeiro, acarretando-lhe dificuldades e inadequações no enfrentamento dessas situações em seu cotidiano de trabalho. Oliveira et al. (2006) destacam que genericamente todo profissional enfermeiro trabalha com o intuito de evitar a morte de seus pacientes. Desdobra-se em cuidados e técnicas específicas de cuidado e assistência para manter a vida dos clientes, posta em risco pela presença de doenças ou também pela realização de procedimentos terapêuticos. $O$ profissional da saúde que convive mais de perto e frequentemente com a morte é o enfermeiro, pois é ele quem passa a maior parte do tempo com o indivíduo hospitalizado.

Para Oliveira e Amorim (2008, p. 27), vive-se em uma sociedade que tem os costumes e a cultura de negar a morte "[...] e apesar dos enfermeiros serem formados para salvar vidas, não se pode anular a necessidade de saber lidar com a Morte. Neste caso, a Morte, apresenta-se como um fracasso ao profissional, visto que este é treinado para salvar vidas e não para perdê-la".

Alia-se a isso, certa regra existente no mundo dos profissionais de saúde que enuncia que o bom profissional é aquele que não se envolve emocionalmente com seus pacientes. Cria-se, portanto, uma situação arriscada para estes profissionais: como lidar com a morte de um paciente e principalmente ajudar a família do mesmo na aceitação do falecimento de um ente querido, mantendo-se distantes e indiferentes, uma vez que todas as pessoas também são mortais e os homens costumam refletir seu próprio fim nos outros? (AGUIAR et al., 2006).

Carvalho et al. (2006, p. 30) dizem que:

O profissional de saúde é finito como todo e qualquer outro ser humano, e também passa por profundos dilemas existenciais quanto ao enfrentamento e vivência da morte em seu cotidiano de trabalho. Na maioria das vezes, esse profissional, ainda como acadêmico, não foi estimulado ou preparado à refletir sobre a morte e o morrer, podendo ser pego de surpresa pelo pesar, e mais, não oferecer uma assistência de qualidade, não conseguindo assistir a pessoa que está morrendo e/ou sua família, em razão da morte se configurar como momento de grande sofrimento e fracasso da ação principal em manter a vida. 
| De Moiras a Tânatos: considerações a respeito da morte e do morrer para os profissionais da Enfermagem|

| Leonardo Mendes Bezerra | Ricardo Carvalho Neves |

Percebe-se então a suma importância que tem a preparação do acadêmico para a morte do paciente. O cuidado humanizado e as relações humanas que necessitam implementar e desenvolver com os pacientes não podem ser improvisados ou feitos de qualquer maneira. Porque, nesse momento, se depara com o problema lançado anteriormente: como ser humano e emocionalmente participativo na última fase da vida de um paciente sem criar nenhum tipo de relação sentimental com o mesmo? (LANA; PASSOS, 2008).

As escolas de enfermagem têm por dever preparar os profissionais para o processo de morte e morrer, para que, além de serem tecnicamente competentes em realizar as técnicas necessárias, sejam capazes de lidar com seus próprios sentimentos, perante o falecimento dos pacientes e usá-los de modo deliberado e humanamente sofisticados. Para Bretas et al. (2006, p. 19), a morte tem proporcionado incômodo e desafios à onipotência dos seres humanos e dos profissionais de saúde, destacando o enfermeiro, “[...] pois os profissionais de saúde são ensinados a cuidar da vida e não da Morte. Prova deste fato é que na maior parte dos cursos de formação de profissionais, não existe uma disciplina curricular que trate do assunto de forma não defensiva e biologicista".

Por não ser um tema fácil, visto que muitas vezes causa sensações de frustração, tristeza, perda, impotência, estresse e culpa, é notório que a universidade, na posição de instituição formadora, tem a obrigação de se preocupar e ter profissionais com sensibilidade para que possam expressar seus sentimentos e aprofundar esta temática no processo de ensino e aprendizagem. Nota-se durante o curso a dificuldade de o estudante ter oportunidade para vivenciar um evento tão complexo (OLIVEIRA; AMORIM, 2008).

O profissional de Enfermagem é educado para a vida e constata-se que o ensino acadêmico preza e prioriza apenas o viver, esquecendo-se desse tema tão inerente à condição humana. Os enfermeiros sofrem sozinhos diante da batalha entre vida e morte, colocando-se frequentemente como impotentes, por não terem tido preparo suficiente para intervir nessa hora (PINHO, 2008).

Exemplo disso está no paciente com câncer, uma doença debilitante e que traz muito sofrimento à pessoa, deixando-a muito dependente dos outros. Aqui se discute se um profissional recém-formado é preparado para estar junto desse paciente, prestando-lhe o cuidado pertinente e resguardando-se do impacto e das consequências psicológicas da possível morte do mesmo (PINHO, 2008).

De acordo com Moreira e Lisboa (2006, p. 47), 
|De Moiras a Tânatos: considerações a respeito da morte e do morrer para os profissionais da Enfermagem |

| Leonardo Mendes Bezerra | Ricardo Carvalho Neves |

[...] o ensino de enfermagem é baseado, principalmente, na aprendizagem das técnicas de cuidado, no saber fazer. Técnicas de prevenção, promoção, cura e reabilitação que possuem protocolos fixos, que orientam passo a passo. Todos os procedimentos são ensinados e o aluno sai preparado para a ação e geralmente a parte reflexiva da profissão fica a desejar.

Ideia que é reforçada por Júnior e Eltink (2011, p. 15), quando afirmam que “[...] no curso de enfermagem também são mais enfatizados os aspectos técnicos e práticos da função de enfermeiro. Há pouca ênfase em questões ligadas à emoção e na preparação para lidar com o assunto morte".

Os estudantes de Enfermagem são treinados para desenvolver uma relação com o paciente segundo os modelos descritos nos livros de Enfermagem que destacam o hábito de cuidar como algo essencial e puramente bom, o qual só trará benefícios para o paciente e o profissional, pois:

O cuidar ajuda a evitar doenças, a promover a saúde, curar ou ajudar os vulneráveis, educar a população e elevar as relações humanas a experiências gratificantes de prazer, segurança, confiança, crescimento e atividade produtiva. Amor, ódio, medo, felicidade, raiva, prazer, ou qualquer outra emoção humana podem receber os efeitos produtores de crescimento, geradores de energia, motivadores e, consistentemente, positivos do cuidar. Todos os demais sentimentos humanos possuem efeitos potencialmente negativos, bem como positivos, mas o cuidar, por sua natureza e definição, é somente e sempre positivo (OLIVEIRA; BRÊTAS; YAMAGUTI, 2007, p. 51).

Assim como Cantídio et al. (2011) registraram que na atualidade a maioria das graduações preparam os estudantes para salvar vidas e aprendem que a morte deve se afastar das práticas das vivências humanas, assim, o findamento não é um elemento muito representativo na vida acadêmica.

[...] apesar de lidar com pessoas, os estudantes vivem como se manipulassem objetos ou coisas, separam completamente o corpo biológico do indivíduo e sacrificam suas emoções ao não se permitirem o envolvimento com os pacientes assistidos e seus familiares, deixando a sensação de trabalho frustrante e incompleto, frente aos experimentos inúteis de evitar o término da vida (CANTÍDIO et al., 2011, p. 34).

Os aspectos psicossociais da morte não estão incluídos na matriz curricular dos cursos de Enfermagem e, quando abordados, ocorrem de maneira superficial e assistemática. Além disso, as disciplinas, como Enfermagem Médico-Cirúrgica, Fundamentos de Enfermagem e Psicologia tratam da temática de forma incipiente, prevalecendo à abordagem tecnicista em detrimento da humanização do cuidado em todas suas dimensões (CANTÍDIO et al., 2011). 
|De Moiras a Tânatos: considerações a respeito da morte e do morrer para os profissionais da Enfermagem|

| Leonardo Mendes Bezerra | Ricardo Carvalho Neves |

Estudos já comprovaram que realmente há uma deficiência na matriz curricular das instituições superiores, quando o assunto é ligado à temática do fim da vida. $\mathrm{Na}$ área da Enfermagem, pouca atenção é dada à questão pelas instituições formadoras que pode ser constatada quando se considera o resultado de pesquisa realizada com estudantes de escolas de Enfermagem brasileiras. Mais de 40\% da população do estudo revelaram não ter aulas sobre o tema morte e morrer em suas escolas e, os que informaram sobre a existência de tais conteúdos, relataram que o assunto é abordado como um subtema de uma disciplina ou matéria principal e varia entre 30 minutos e 10 horas (CARVALHO et al., 2006).

Cantídio et al. (2011) relataram que alguns acadêmicos apenas recordam que o tema foi discutido em algumas disciplinas, porém de forma insuficiente para tal abordagem, declarando terem sido simplistas as discussões e os conteúdos curriculares sobre a morte, durante a formação. Aliada a essa formação profissional, destacam-se as disciplinas Filosofia da Saúde, Antropologia da Saúde e Psicologia da Saúde, como coligadas à discussão do processo morte-morrer e são disciplinas humanísticas que possuem caráter holístico.

O estudo de Heidegger (2005) colabora com a temática quando aborda que o serno-mundo é visto como uma totalidade que não tem a possibilidade de ser decomposta e particionada em fragmentos isolados, contrapondo à visão cartesiana. Neste sentido podem-se considerar os diversos aspectos do mundo e as diferentes formas dos seres humanos coexistirem.

Assim, a visão da existência humana caracteriza-se como pontos de resistência do ato de pensar sobre o próprio pensamento. Isso implica em dizer que, conforme Bachelard (1996), para se estudar o processo de morte-morrer não se deve levar, em última instância, apenas os questionamentos, mas sim o processo reflexivo que visa também analisar as respostas relativas à temática abordada. As respostas são importantes e esse processo de preferência por elas é o que se pode chamar de instinto de conservação do pensamento científico, indicando o funcionamento da saúde, seu sentido e suas representações como se estas não tivessem sustentação na realidade social, histórica, existencial e humana.

Assim, é necessário que a área da enfermagem atue de forma interdisciplinar e multidisciplinar por compreender que as naturezas humanas, em suas múltiplas dimensões, se expressam em fases evolutivas. No sentido científico, a última etapa dessa evolução encontra-se na morte. Consequentemente, o preparo do estudante ainda enfatiza o lidar com a vida no que tange aos aspectos técnicos e práticos da função profissional, com pouca ênfase em questões emocionais e na instrumentalização para o duelo constante entre 
| De Moiras a Tânatos: considerações a respeito da morte e do morrer para os profissionais da Enfermagem |

| Leonardo Mendes Bezerra | Ricardo Carvalho Neves |

vida e morte. Mesmo diante do enfrentamento de situações de morte, durante as práticas curriculares, não tem sido oportunizado ao aluno a discussão dessas situações (BELLATO et al., 2007; BERNIERI; HIRDES, 2007).

Com essa falha, supõe-se que o acadêmico seja preparado apenas para o "lado bom" do exercício da profissão, para as situações em que tudo vai dar certo e o paciente se recuperará perfeitamente. A outra possibilidade, cujos esforços literalmente serão em vão, em função do falecimento do cliente, é esquecida. Assim, pode-se afirmar que “[...] essa falta de reflexão leva à frustração do estudante e reforça o sentimento de fracasso frente à ação principal em manter a vida" (BRÊTAS et al., 2007, p. 20).

No cotidiano da vida acadêmica, emergem sentimentos de frustração e culpa que fazem com que o estudante sinta-se despreparado e afaste-se do enfermo com morte iminente, quando se depara com essa situação no cumprimento das práticas curriculares. Os sentimentos de frustração e culpa caracterizam-se pela impotência, tristeza, medo e indiferença, sendo o distanciamento desse tipo de paciente uma estratégia utilizada pelos estudantes para amenizar a situação. Neste sentido, Cantídio et al. (2011, p. 46) defendem que:

[...] para os futuros profissionais atuarem durante a finitude, desenvolvendo suas ações com competência, eficácia e sensibilidade, necessita-se de preparo no decorrer do processo de formação. Para isso, as instituições de ensino devem ter o compromisso com essa formação, ensinando a cuidar e lidar com pacientes terminais e seus familiares, não só enfocando o conhecimento teórico-prático visível, mas também o subjetivo vivido, fornecendo informações importantes para melhor se enfrentar o encontro e a vivência da morte, a fim de proporcionar cuidado de qualidade aos envolvidos. Não bastam novas disciplinas ou incorporações de conteúdos sobre o tema da morte para ensiná-la na formação. É necessário, sobretudo, reflexões sobre o sentido da vida e do cuidar, para que se abra espaço à construção do processo ensino/aprendizado.

Autores como Cantídio et al. (2011), Silva (2009) e Costa e Lima (2006) apontam para a necessidade da formação de grupos de estudos e discussões como estratégia para minimizar a ansiedade da equipe em relação ao confronto com a morte e suas dificuldades. É importante a reformulação dos currículos dos cursos de Enfermagem para que sejam inseridos momentos de vivência e reflexão acerca da perda e do luto, para que os profissionais não se sintam despreparados e desamparados ao lidarem com a realidade hospitalar (JÚNIOR; ELTINK, 2011).

O estágio supervisionado é um momento ideal, no qual essas discussões podem ser abordadas, pois nesse momento o acadêmico tem os primeiros contatos com os casos reais 
| De Moiras a Tânatos: considerações a respeito da morte e do morrer para os profissionais da Enfermagem|

| Leonardo Mendes Bezerra | Ricardo Carvalho Neves |

e é maior a possibilidade de se deparar com a situação de morte. Bernieri e Hirdes (2007, p. 22) destacam a importância dessa discussão sobre a morte também no campo de estágio:

[... como forma de confrontar a teoria com a prática onde os alunos presenciariam e/ou vivenciariam as experiências trocadas nos debates, e daí tirariam suas conclusões, onde cada um formularia sua opinião, estando mais preparado para o enfrentamento da situação fora da faculdade, seja no exercício da profissão, seja na vida pessoal.

No hospital, no exercício profissional, é o momento e o lugar onde se exigirá do estudante uma postura livre de tabus, conceitos ou religião, e participativa numa relação de ajuda e cuidado. Se não houver um preparo emocional e psicológico para os profissionais lidarem com esse assunto, dificilmente eles terão uma postura adequada diante da morte (AGUIAR et al., 2006).

Finalmente, recomenda-se que sejam incentivados estudos sobre essa temática nas instituições de ensino superior, como estratégia para que a prática do assistir no processo de morrer seja humanizada e a fim de que se desvele o fenômeno da morte com o diálogo dos estudos filosóficos, psicológicos, antropológicos, teológicos, biológicos e empíricos. Caso contrário, corre-se o risco de perpetuar a inadequação do enfermeiro frente ao indivíduo com morte iminente, negando não apenas a morte, mas desrespeitando a dignidade da pessoa que está morrendo e descumprindo o juramento de respeitar a vida desde a concepção até a morte (VARGAS, 2010).

\section{CONSIDERAÇÕES FINAIS}

No decorrer da história da humanidade percebeu-se que a morte sempre foi um tema bastante instigante e discutido por filósofos, teólogos e cientistas, o que indica, mesmo em civilizações arcaicas, a morte nunca foi negada e investigada a fim de fundamentar explicações significativas. Ademais destacou-se que uma das características significativas dos seres humanos é a atribuição de valores e de significados às pessoas. Isso tem proporcionado, no campo da enfermagem, o sofrimento e despreparo científico e teórico para orientar os familiares no alívio e na superação da perda do ente. Apresentaram-se argumentos que essa orientação dos enfermeiros é uma das atribuições que mais exigem cautela e preparo, por se tratar com múltiplos elementos envolvidos.

Verificou-se também que é preciso estimular os acadêmicos de enfermagem a refletirem sobre o extinguir da vida humana sob a luz da assistência de qualidade e com a abordagem holística da profissão. A imparcialidade tem sido a principal estratégia de 
| De Moiras a Tânatos: considerações a respeito da morte e do morrer para os profissionais da Enfermagem|

| Leonardo Mendes Bezerra | Ricardo Carvalho Neves |

enfrentamento verificada na Enfermagem. Atualmente, observa-se que a morte tem sido tratada com indiferença, como mecanismo de defesa dos enfermeiros, uma vez que raramente são preparados na graduação para atuarem com a ciência tanatológica.

Para que não haja essa indiferença é necessário que as universidades proporcionem um preparo no sentido de melhor capacitar os alunos para a morte. Daí surge a importância de uma educação para a morte e que os conteúdos e as experiências dos professores possam se integrar de modo transdisciplinar, interdisciplinar e multidisciplinar a fim de permear os conteúdos disciplinares e também salientar a importância de projetos formais dessa natureza e a sua inclusão na formação dos enfermeiros assistenciais.

\section{REFERÊNCIAS}

AGRA, L. M. C.; ALBUQUERQUE, L. H. M. Tanatologia: uma reflexão sobre a Morte e o morrer. Pesquisa Psicológica (Online), Maceió, ano 1, n. 2, jan. 2008. Disponível em: < http://www.pesquisapsicologica.pro.br> . Acesso em: 11 abr. 2011.

AguiAR, I. R.; VelosO, T. M. C.; PINHEIRO, A. K. B.; XIMENES, L. B. O envolvimento do enfermeiro no processo de morrer de bebês internados em Unidade Neonatal. Acta Paulista de Enfermagem, v. 19, n. 2, p. 131-137, 2006.

BACHELARD, Gaston. A formação do espírito científico: contribuição para uma psicanálise do conhecimento. Rio de Janeiro: Contraponto, 1996.

BARDIN, L. Análise de conteúdo. Lisboa: Edições 70, 2016.

BELlATO, R.; ARAÚJO, A. P.; FERREIRA, H. F.; RODRIGUES, P. F. A abordagem do processo do morrer e da Morte feita por docentes em um curso de graduação em Enfermagem. Acta Paulista de Enfermagem, v. 20, n. 3, p. 255-263, 2007.

BELLATO, R., CARVALHO, E. C. O jogo existencial e a ritualização da morte. Revista Latino-Americana de Enfermagem, Ribeirão Preto, v. 13, n. 1, p. 99-104, jan./ fev. 2005.

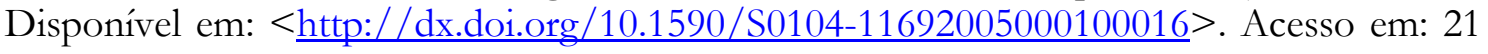
ago. 2017.

BERNIERI, J.; HIRDES, A. O preparo dos acadêmicos de Enfermagem brasileiros para vivenciarem o processo morte-morrer. Texto \& Contexto - Enfermagem, v. 16, n. 1, p. 89-96, jan./mar. 2007. Disponível em: <http://www.scielo.br/pdf/tce/v16n1/a11v16n1>. Acesso em: 21 ago. 2017.

OLIVEIRA, J. R.; BRETAS, J. R. S.; YAMAGUTI, L. A morte e o morrer segundo representações de estudantes de enfermagem. Revista da Escola de Enfermagem da USP, v. 41, n. 3, p. 386-394, 2007. Disponível em: <http://www.scielo.br/pdf/reeusp/v41n3/07.pdf>. Acesso em: 11 jun. 2011. 
|De Moiras a Tânatos: considerações a respeito da morte e do morrer para os profissionais da Enfermagem|

| Leonardo Mendes Bezerra | Ricardo Carvalho Neves |

CANTÍDIO F. S.; VIEIRA, M. A.; SENA, R. R. Significado da morte e de morrer para os alunos de enfermagem. Investigación y Educación en Enfermería, Medellín, v. 29, n. 3, p. 407-418, out./dez. 2011. Disponível em: <https://goo.gl/zvqjv8>. Acesso em: 21 ago. 2017.

CAPUTO, R. F. O homem e suas representações sobre a Morte e o morrer: um percurso histórico. Revista Multidisciplinar da UNIESP - Saber Acadêmico, n. 6, dez. 2008. Disponível em: <http://www.uniesp.edu.br/revista/revista6/pdf/8.pdf $>$. Acesso em: 25 jun. 2012.

CARVALHO, L. S.; OLIVEIRA, M. A. S.; PORTELA, S. C.; SILVA, C. A.; OLIVEIRA, A. C. P.; CAMARGO, C. A. A morte e o morrer no cotidiano de estudantes de Enfermagem. Rev. enferm. UERJ, v. 14, p. 551-557, 2006.

COMBINATO, D. S.; QUEIROZ, M. S. Morte: uma visão psicossocial. Estudos de Psicologia, v. 11, n. 2, p. 209-216, 2006.

COSTA, J. C.; LIMA, R. A. G. Luto da equipe: revelações dos profissionais de Enfermagem sobre o cuidado à criança/adolescente no processo de morte e morrer. Revista Latino-Americana de Enfermagem, Ribeirão Preto, v. 13, n. 2, p. 151-157, mar./abr. 2005. Disponível em: < http://dx.doi.org/10.1590/S0104-11692005000200004>. Acesso em: 21 ago. 2017.

CUSTÓDIO, M. R. M. O processo de morte e morrer no enfoque dos acadêmicos de enfermagem. Encontro: Revista de Psicologia, v. 13, n. 18, p. 127-142, 2010.

GIACCOIA JÚNIOR, O. A visão da morte ao longo do tempo. Medicina, Ribeirão Preto, v. 38, n. 1, p. 13-19, 2005.

HEIDEGGER, Martin. Ser e Tempo. Tradução de Márcia Sá Cavalcante Schubach. 15. ed. Rio de Janeiro: Vozes, 2005.

JÚNIOR L.; ELTINK C.F. A visão do graduando de enfermagem perante a morte do paciente. J Health Sci Inst., v. 29, n. 3, p. 176-182, 2011.

LANA, S. O.; PASSOS, A. B. B. Preparo dos acadêmicos de enfermagem no processo de morte e morrer. Revista Enfermagem Integrada, Ipatinga - MG, v. 1, n. 1, p. 80-90, nov./dez. 2008. Disponível em: $<$ https://www.unilestemg.br/enfermagemintegrada/artigo/v1/samantha lana e ana beat riz passos.pdf $>$. Acesso em: 21 ago. 2017.

MAFRA, V. A. V. F.; DALPRÁ, L. R. O processo de morte-morrer sob a ótica do graduando de Enfermagem. 2009. Disponível em: $<$ http://www.webartigos.com/artigos/o-processo-de-Morte-morrer-sob-a-otica-dograduando-de-Enfermagem/28438/>. Acesso em: 22 jul. 2012.

MOREIRA, A. C.; LISBOA, M. T. L. A Morte - entre o público e o privado: reflexões para a prática profissional de Enfermagem. Revista Enfermagem UERJ, Rio de Janeiro, v. 14, n. 3, set. 2006. 
| De Moiras a Tânatos: considerações a respeito da morte e do morrer para os profissionais da Enfermagem |

|Leonardo Mendes Bezerra | Ricardo Carvalho Neves |

MOTA, M. S.; GOMES, G. C.; COELHO, M. F.; LUNARDI FILHO, W. D.; SOUSA, L. D. Reações e sentimentos de profissionais da Enfermagem frente à Morte dos pacientes sob seus cuidados. Rev Gaúcha Enferm., Porto Alegre, v. 32, n. 1, p. 129-135, mar. 2011.

OLIVEIRA S.G.; QUINTANAL, A.M.; BERTOLINO, K.C.O. Reflexões acerca da Morte: um desafio para a Enfermagem. Rev Bras Enferm., Brasília, v. 63, n. 6, p.10771080, nov./dez. 2010.

OLIVEIRA, E. C. et al. Percepções e sentimentos de acadêmicos de Enfermagem sobre a morte e o processo de morrer. Revista Científica da FAMINAS, Caratinga, 2006.

OLIVEIRA, W. I. A.; AMORIM, R. C. A morte e o morrer no processo de formação do enfermeiro. Revista Gaúcha de Enfermagem, Porto Alegre, v. 2, n. 3, p. 191-198, jun. 2008.

PINHO, L. M. O. Vivenciando o processo de morte na formação do Enfermeiro. 2008. 95 f. Tese (Doutorado em Ciências da Saúde) - Programa Multiinstitucional de PósGraduação - Convênio Rede Centro-Oeste (UnB/UFG/UFMS), Goiânia, 2004. Disponível em: < https://goo.gl/H6SLrk>. Acesso em: 14 set. 2011.

PINHO, L. M. O.; BARBOSA, M. A. A morte e o morrer no cotidiano de docentes de enfermagem. Revista de Enfermagem UERJ, Rio de Janeiro, v. 16, n. 2, p. 243-248, abr. 2008. Disponível em: < https://goo.gl/VJjEuY>. Acesso em: 18 abr. 2011.

SANTOS, J. L., BUENO, S. M. V. A questão da morte e os profissionais de Enfermagem. Rev. enferm. UERJ, Rio de Janeiro, v. 18, n. 3, p. 484-487, jul./set. 2010.

SANTOS, J. L., BUENO, S. M. V. Educação para a morte a docentes e discentes de Enfermagem: revisão documental da literatura científica. Rev Esc Enferm USP, v. 45, n. 1, p. 272-276, 2011.

SHIMIZU, H. E. Como os trabalhadores de Enfermagem enfrentam o processo de morrer. Rev Bras Enferm, v. 60, n. 3, maio/jun. 2007.

SILVA, A. L. L.; RUIZ, E. M. Cuidar, morte e morrer: significações para profissionais de Enfermagem. Rev. Estudos de Psicologia, PUC-Campinas, v. 20, n. 1, p. 15-25, jan./abr. 2003.

SILVA, J. Preparo e percepções da equipe de Enfermagem no processo de morte e morrer. Revista Hórus, Londrina, v. 4, n. 1, p. 232-245, 2009.

TAKAHASHI, C. B.; CONTRIN, L. M.; BECCARIA, L. M.; GOUDINHO, M. V.; PEREIRA, R. A. M. Morte: percepção e sentimentos de acadêmicos de Enfermagem. Arq Ciênc Saúde, v. 15, n. 3, p. 132-138, jul./set. 2008.

VARGAS, D. Morte e morrer: sentimentos e condutas de estudantes de Enfermagem. Acta Paul Enferm, v. 23, n. 3, p. 404-410, 2010.

WEST, M. L. Hesiod: Theogony. Oxford-RU: Oxford University Press, 1966. 